\title{
Measuring the accuracy of self-reported height and weight in a community-based sample of young people
}

\author{
Anna L Bowring ${ }^{1 *}$, Anna Peeters ${ }^{2}$, Rosanne Freak-Poli ${ }^{2,3}$, Megan SC Lim, ${ }^{1,3}$, Maelenn Gouillou' ${ }^{1}$ and \\ Margaret Hellard ${ }^{1,3,4}$
}

\begin{abstract}
Background: Self-reported anthropometric data are commonly used to estimate prevalence of obesity in population and community-based studies. We aim to: 1) Determine whether survey participants are able and willing to self-report height and weight; 2) Assess the accuracy of self-reported compared to measured anthropometric data in a community-based sample of young people.
\end{abstract}

Methods: Participants (16-29 years) of a behaviour survey, recruited at a Melbourne music festival (January 2011), were asked to self-report height and weight; researchers independently weighed and measured a sub-sample. Body Mass Index was calculated and overweight/obesity classified as $\geq 25 \mathrm{~kg} / \mathrm{m}^{2}$. Differences between measured and self-reported values were assessed using paired t-test/Wilcoxon signed ranks test. Accurate report of height and weight were defined as $<2 \mathrm{~cm}$ and $<2 \mathrm{~kg}$ difference between self-report and measured values, respectively. Agreement between classification of overweight/obesity by self-report and measured values was assessed using McNemar's test.

Results: Of 1405 survey participants, $82 \%$ of males and $72 \%$ of females self-reported their height and weight. Among 67 participants who were also independently measured, self-reported height and weight were significantly less than measured height $(p=0.01)$ and weight $(p<0.01)$ among females, but no differences were detected among males. Overall, $52 \%$ accurately self-reported height, 30\% under-reported, and 18\% over-reported; $34 \%$ accurately self-reported weight, 52\% under-reported and 13\% over-reported. More females (70\%) than males (35\%) under-reported weight $(\mathrm{p}=0.01)$. Prevalence of overweight/obesity was $33 \%$ based on self-report data and $39 \%$ based on measured data $(p=0.16)$.

Conclusions: Self-reported measurements may underestimate weight but accurately identified overweight/obesity in the majority of this sample of young people.

Keywords: Body height, Body weight, Body mass index, Overweight, Obesity self-report, Validity, Young people

\section{Background}

In Australia, obesity is a national health priority, and approximately one quarter of young adult Australians are overweight or obese [1]. This is a concern for immediate social and health problems, as well as risk of future obesity in adulthood and associated chronic health problems, such as type II diabetes, cardiovascular diseases,

\footnotetext{
* Correspondence: annab@burnet.edu.au

${ }^{1}$ Centre for Population Health, Burnet Institute, 85 Commercial Rd Melbourne, VIC 3004, Australia

Full list of author information is available at the end of the article
}

musculoskeletal disease and some cancers [1]. Data on prevalence and trends in obesity in young people are needed to inform, monitor, and evaluate appropriate policy and interventions.

Body mass index (BMI) is widely used as a measure of obesity due to its simple derivation from height and weight. Height and weight are commonly self-reported in population health surveys for ease of collection [2]. In contrast to direct measurement, self-report enables a large number of individuals to be sampled at relatively

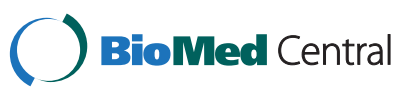


minimal cost, time, and resources and the survey tool can be administered face to face, by telephone or online.

Self-reported height and weight may be affected by response or recall bias. It is commonly found that weight is underestimated while height is often overestimated [3-8], leading to underestimation of BMI $[5,7,8]$. Some studies have identified a greater discrepancy in self-reported and measured height and weight among certain groups, including overweight or obese individuals compared to healthy or underweight individuals [6,7,9-12], females [7-9,12,13], dieters compared to non-dieters, nonsmokers compared to smokers [11,14], and older individuals $[7,9,11]$. Such systematic error may lead to lower prevalence estimates of overweight and obesity and systematic bias in studies examining the relationship between obesity and health outcomes dependent on selfreported measurements. In the Australian context, from a telephone-recruited population survey in Adelaide, classification of overweight/obesity among 18-24 year olds was $6.3 \%$ through self-report data and $10.1 \%$ through measured data,[13]; while in the 1995 Australian National Health Survey, classification of overweight/obesity among 15-19 year olds was $18 \%$ and $12 \%$ of males and females, respectively, through self-report data and $25 \%$ and $19 \%$ of males and females, respectively, through measured data [6].

In spite of these findings, there remains a lack of data reporting the willingness and accuracy of young people to self-report height, weight, and derived BMI, particularly in community-based settings. Traditional methods of recruiting young people into population surveys, such as random digit dialling and school-based recruitment, are subject to increasing barriers affecting participation, tracking, and retention, such as high mobility, changes in telephone use and technology, and non-school attendance $[15,16]$. Community-based recruitment provides an alternative means to recruit large numbers of young people, and we have previously shown how periodic recruitment from a music festival can be used for surveillance in young people $[17,18]$. In this setting, use of self-reported measurements would be preferable, given the substantial added time and resources required to independently measure participants.

Here we use participants in a risk behaviour survey to determine the accuracy of self-reported height and weight in Australian 16-29 year olds in a communitybased setting. Specifically, the aims of this study were:

1) To determine whether young people participating in a risk behaviour survey are able and willing to provide self-reported height and weight data; and

2) To assess the accuracy of self-reported height, weight and BMI compared to measured values in a community-based sample of young people.

\section{Methods}

\section{Participants and procedure}

Participants were recruited at the Melbourne Big Day Out (BDO) - one day music festival in January 2011 - as part of an ongoing behavioural surveillance system that has been undertaken at the BDO since 2005 [17-19]. A convenience sample of young people aged 16-29 years was recruited by approximately 20 trained researchers (Figure 1). Participants approached or were approached by researchers in and around a study market stall in the food and market area of the festival . Recruitment occurred between 10am and 3pm. Once the survey was explained, participants self-completed a consent form and short questionnaire taking approximately 10 minutes.

The structure of the market stall set up meant there was one measuring station for height and weight. After completing the questionnaire, participants were invited to have their height and weight measured if approximately three or less participants were waiting to use the measuring station.

\section{Questionnaire}

A core set of questions about drug and alcohol use and sexual risk behaviours is asked annually in the BDO survey $[17,18]$. In 2011, participants were additionally asked to self-report their height in centimetres (without shoes) and weight in kilograms (without clothes and shoes) with an option for "don't know" in both questions.

\section{Measures}

\section{Anthropometry}

When submitting their completed survey, a subset of individuals was invited to have their height and weight measured by a trained research assistant (Figure 1). As outlined above, invitation was based upon the availability of the measurement station. Participants were measured without shoes and wearing light clothes using digital scales and a portable stadiometer. Height and weight were measured to the nearest $1 \mathrm{~cm}$ and $0.1 \mathrm{~kg}$, respectively.

To link measurements to the participants' surveys, measurements were labelled using either the survey identification number or a "porn star name", a novel anonymous identifier derived from name of first pet and name of first street [20], which was also reported in the questionnaire.

BMI for both self-reported and measured values was calculated as weight $(\mathrm{kg})$ divided by height squared $\left(\mathrm{m}^{2}\right)$. For participants aged 18 years and older, overweight and obesity were classified using the standard international adult BMI ranges: underweight (BMI <18.5), healthy weight $(\mathrm{BMI}=18.5-24.9)$, overweight $(\mathrm{BMI}=25.0-29.9)$, or obese (BMI >30). [21,22] For participants aged under 


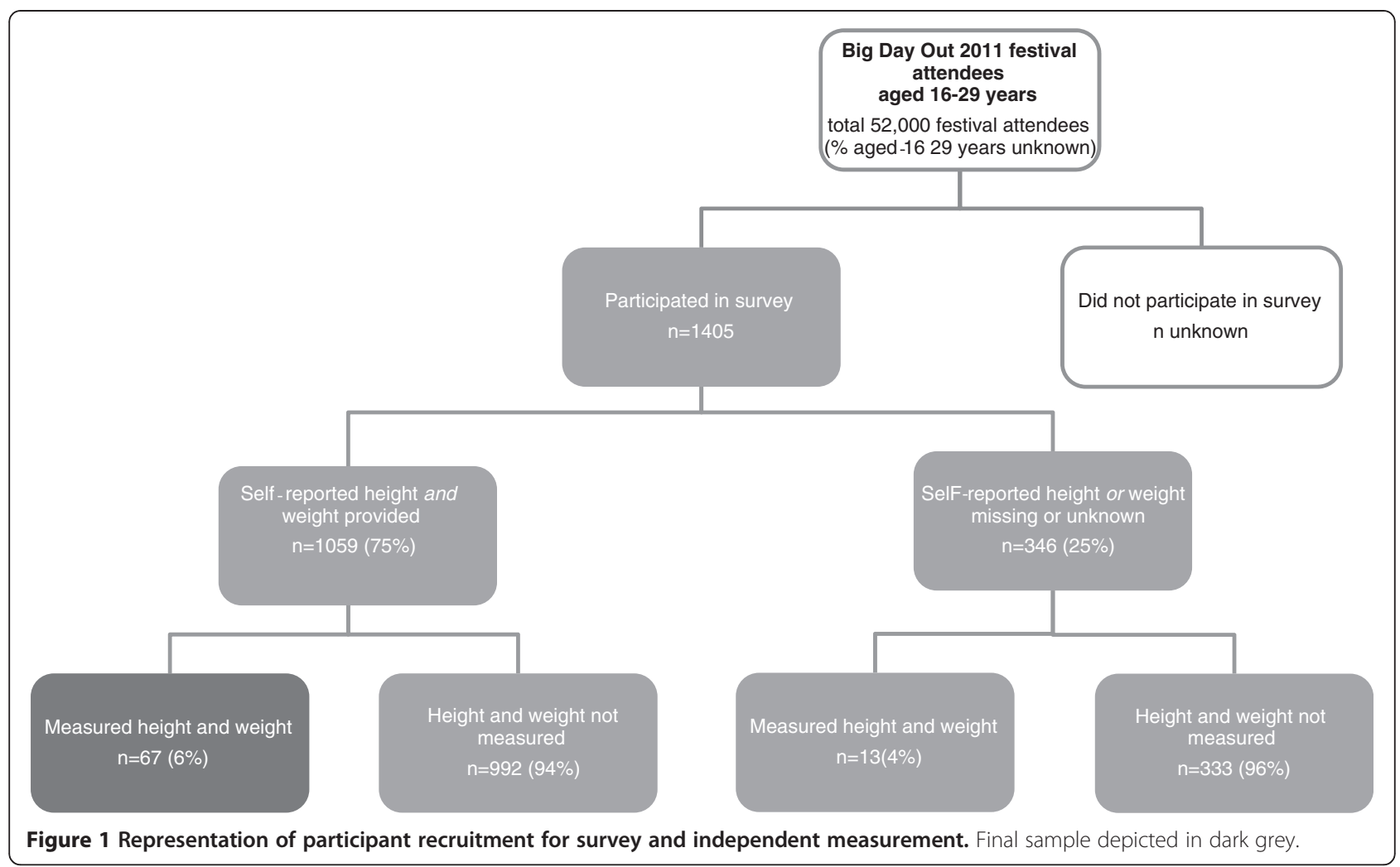

18 years, age and sex specific BMI cut-offs for overweight and obesity were used, as defined by the International Obesity Task Force.[23] For the purpose of this research, obesity classification was dichotomised as non-overweight $\quad(\mathrm{BMI}<25.0)$ and overweight/obese $(\mathrm{BMI} \geq 25.0)$.

\section{Socio-demographics indicators}

A range of self-reported demographic indicators were assessed: sex (male, female); age (16-19, 20-29 years); born in Australia (yes, no); area of residence (major, non-major city); living arrangements (if live with parents/partner; yes, no); post-high school education (if completed or in the process of completing; yes, no); recreational income $(<\$ 120, \geq \$ 120$ per week). Area of residence was classified from Australian postcodes of residence using the Australian Standard Geographical Classification (ASGC) Remoteness Areas system [24]. Recreational income was defined as money available for spending or saving, not including essential living costs or tax.

\section{Analysis}

Data were entered into a Microsoft Access database and statistical analysis was conducted in Stata version $11[25]$.

To assess factors associated with survey participants' $(\mathrm{n}=1405)$ ability and willingness to provide self-report height and weight measurements, participants who did and did not self-report height and weight were compared by demographic indicators using chi-square tests of proportion (Figure 1).

Among those with self-reported height and weight $(\mathrm{n}=1059)$, participants with and without measurements taken were compared using chi-square tests of proportion and Wilcoxon rank-sum test.

The final analysis was limited to participants with both self-reported and measured height and weight $(n=67)$ (Figure 1). Accuracy of self-report height, weight, and derived BMI compared to corresponding measured values was assessed in four ways:

i. Test of equality between measured and self-reported mean or median was assessed using a paired $t$-test or Wilcoxon signed ranks test, respectively, both overall and stratified by sex, age group, and obesity classification categories.

ii. Correlation of self-report to measured values was calculated using Pearson correlation coefficient or Spearman rank correlation coefficient according to distribution of both self-reported and measured height, weight and BMI.

iii. The proportion of individuals who accurately, under- and over- reported their weight/height was compared using a Fisher's exact test. Accurate report of weight/height was defined as less than $2 \mathrm{~kg} / 2 \mathrm{~cm}$ 
absolute difference between self-report and measured weight/height given an acceptable margin of error, based on previous studies [26]. Under-report of height/weight was defined as self-report $\geq 2 \mathrm{~cm} / 2 \mathrm{~kg}$ less than measured values; over-report of weight/height was defined as self-report being $\geq 2 \mathrm{~cm} / 2 \mathrm{~kg}$ more than measured values. The proportion of participants misreporting their height or weight by five or more kilograms was also calculated.

iv. Prevalence of overweight/obesity based on selfreport and measured data was compared using twosided exact McNemar's test. Misclassification of overweight/obesity was measured in terms of sensitivity and specificity with exact binomial 95\% confidence intervals (CI), whereby 100\% indicates maximum agreement between self-reported and measured classification.

Significance level was 0.05 in all analyses.

\section{Ethics}

Ethical approval was granted by the Alfred Hospital Human Research Ethics Committee (number 326/08).

\section{Results}

In total, 1405 questionnaires were completed (see Figure 1). Self-reported height was unknown in 237 (18\%) and missing in 28 (2\%) questionnaires; self-reported weight was unknown in $148(11 \%)$ and missing in $13(1 \%)$ questionnaires. Overall, 1059 (75\%) participants selfreported both height and weight. Comparatively, females, 16-19 year olds, those without post-high school education, those who live with their parents, and those who did not live with a partner were significantly more likely than their counterparts to have self-reported height and/ or weight unknown or missing (all $\mathrm{p}<0.01$ )( Table 1 ).

Eighty survey participants had height and weight independently measured. Amongst survey participants providing self-reported height and weight, participants with

Table 1 Comparison of participant characteristics and risk behaviours by self-report height and weight status

\begin{tabular}{|c|c|c|c|c|c|}
\hline & \multicolumn{2}{|c|}{ Self-reported height and weight } & \multicolumn{2}{|c|}{ Self-reported height and/or weight missing/unknown } & \multirow[t]{2}{*}{ p-value } \\
\hline & $\mathbf{n}$ & $\%$ & n & $\%$ & \\
\hline TOTAL & 1059 & 75 & 346 & 25 & \\
\hline Sex & & & & & $<0.01$ \\
\hline Male & 436 & 82 & 99 & 19 & \\
\hline Female & 623 & 72 & 247 & 28 & \\
\hline Median age (IQR) & 19.7 & $(18.0-22.9)$ & 18.3 & $(17.1-20.7)$ & $<0.01$ \\
\hline $16-19$ & 558 & 70 & 240 & 30 & \\
\hline $20-29$ & 501 & 83 & 106 & 17 & \\
\hline Post high-school education ${ }^{2}$ & & & & & $<0.01$ \\
\hline Yes & 485 & 80 & 122 & 20 & \\
\hline No & 561 & 72 & 219 & 28 & \\
\hline Lives with parent/s & & & & & $<0.01$ \\
\hline Yes & 669 & 72 & 266 & 28 & \\
\hline No & 369 & 83 & 77 & 17 & \\
\hline Lives with partner & & & & & $<0.01$ \\
\hline Yes & 125 & 87 & 19 & 13 & \\
\hline No & 912 & 74 & 324 & 26 & \\
\hline Recreational income ${ }^{3}$ & & & & & 0.10 \\
\hline$<\$ 120$ per week & 703 & 74 & 245 & 26 & \\
\hline$\geq \$ 120$ per week & 331 & 78 & 92 & 22 & \\
\hline \multicolumn{6}{|l|}{ Area of residence 4} \\
\hline Major city & 697 & 75 & 232 & 25 & 0.88 \\
\hline Non-major city & 316 & 75 & 103 & 25 & \\
\hline
\end{tabular}

${ }^{1}$ Chi-square test of proportions, comparing participants with self-reported height and weight to participants with self-reported height or weight missing/unknown.

${ }^{2}$ Post-high school education defined as having completed or in the process of completing post-high school education.

${ }^{3}$ Recreational income defined as money available for spending or saving, not including essential living costs or tax.

${ }^{4}$ Area of residence classified using Australian Standard Geographical Classification (ASGC).

Remoteness Areas (RA) system, whereby RA 1 is coded major city; RA 2-5 is coded non-major city.

Significant $p$-values $(p<0.05)$ shown in boldface.

IQR - inter-quartile range 
(6\%) and without (94\%) independent anthropometric measurement did not differ by demographic characteristics (all $\mathrm{p} \geq 0.08$ ).

The final sample is based on 67 participants with complete self-reported and measured height and weight (Figure 1); 51\% were male, the median age was 20.1 years, 37\% had post-high school education, $67 \%$ lived in a major-city, 57\% lived with their parent(s), and 58\% had $\$ 120$ or less recreational income per week.

\section{Accuracy of self-reported height, weight, and BMI compared to measured values}

As a continuous variable, self-reported and measured height did not significantly differ overall $(p=0.06)$, but mean self-reported height was $2.3 \mathrm{~cm}$ less than mean measured height among females $(\mathrm{p}=0.01)$ (Table 2). Median self-reported weight was two kilos less than median measured weight $(\mathrm{p}<0.01)$. When stratified by age group, sex, and obesity classification, self-reported weight remained significantly lower than measured weight in all sub-categories with the exception of males. Self-reported BMI did not differ from measured BMI overall or when stratified.

Correlations between self-reported and measured values for height and weight were high (Table 2); correlation was equal to or greater than 0.92 for all values and sub-categories with the exception of height among females, with correlation of 0.84 . Correlation of selfreported and measured BMI was moderately high for all sub-groups with the exception among overweight or obese individuals, in which correlation was only 0.40 .

Overall, $52 \%$ of participants accurately self-reported their height (within $2 \mathrm{~cm}$ ), 30\% under-reported, and $18 \%$ over-reported their height (Table 3). There was a tendency for more males than females to over-report their height $(\mathrm{p}=0.16)$.

Overall, 34\% of participants accurately self-reported their weight (within $2 \mathrm{~kg}$ ), 52\% under-reported and 13\% overreported their weight (Table 3). Significantly more females (70\%) than males (35\%) under-reported their weight by at

Table 2 Comparison of measured and self-reported values for height, weight, and BMI overall and by sex, age group, and obesity classification

\begin{tabular}{|c|c|c|c|c|c|c|c|c|}
\hline & & & \multicolumn{2}{|c|}{ Measured } & \multicolumn{2}{|c|}{ Self-reported } & \multirow{2}{*}{$\begin{array}{l}\text { Pearson correlation } \\
\text { between measured } \\
\text { and self-reported }\end{array}$} & \multirow{2}{*}{$\begin{array}{c}\text { Test of equality between } \\
\text { measured and } \\
\text { self-reported, p-value }\end{array}$} \\
\hline & & & Mean (SD) & Median & Mean (SD) & Median & & \\
\hline \multirow[t]{3}{*}{ Total } & \multirow[t]{3}{*}{$(n=67)$} & Height (cm) & 173.7 (9.8) & 175.0 & 172.7 (11.9) & 174.0 & 0.94 & 0.06 \\
\hline & & Weight (kg) & $72.0(14.7)$ & 70.2 & $70.1(14.5)$ & 68.0 & $0.96^{*}$ & $<0.01^{*}$ \\
\hline & & $\mathrm{BMI}\left(\mathrm{kg} / \mathrm{m}^{2}\right)$ & 23.7 (3.2) & 23.2 & $23.4(3.2)$ & 23.0 & 0.84 & 0.16 \\
\hline \multirow[t]{6}{*}{ Sex } & \multirow[t]{3}{*}{ Males $(n=34)$} & Height (cm) & $180.2(7.5)$ & 180.0 & $180.5(8.5)$ & 180.0 & 0.94 & 0.66 \\
\hline & & Weight (kg) & $80.2(14.0)$ & 78.8 & $79.2(13.2)$ & 80.0 & $0.92^{*}$ & $0.28^{*}$ \\
\hline & & $\mathrm{BMI}\left(\mathrm{kg} / \mathrm{m}^{2}\right)$ & $24.6(3.3)$ & 24.5 & $24.2(2.8)$ & 23.3 & 0.85 & 0.21 \\
\hline & \multirow[t]{3}{*}{ Females $(n=33)$} & Height (cm) & 166.9 (6.9) & 165.0 & $164.6(9.3)$ & 164.0 & 0.84 & 0.01 \\
\hline & & Weight (kg) & $63.6(9.9)$ & 63.1 & $60.8(8.8)$ & 60.0 & 0.93 & $<0.01$ \\
\hline & & $\mathrm{BMI}\left(\mathrm{kg} / \mathrm{m}^{2}\right)$ & $22.8(2.9)$ & 22.0 & $22.5(3.4)$ & 21.1 & 0.82 & 0.44 \\
\hline \multirow{6}{*}{$\begin{array}{l}\text { Age group } \\
\text { (years) }\end{array}$} & \multirow[t]{3}{*}{$16-19(n=33)$} & Height (cm) & $173.6(11.0)$ & 172.0 & 172.4 (13.6) & 172.0 & 0.92 & 0.22 \\
\hline & & Weight (kg) & $70.2(14.7)$ & 68.0 & $68.1(14.6)$ & 65.0 & $0.94^{*}$ & $0.01 *$ \\
\hline & & BMI $\left(\mathrm{kg} / \mathrm{m}^{2}\right)$ & $23.1(2.9)$ & 22.0 & $22.8(3.1)$ & 22.6 & 0.76 & 0.39 \\
\hline & \multirow[t]{3}{*}{$20-29(n=34)$} & Height (cm) & $173.8(8.7)$ & 175.8 & $172.9(10.2)$ & 175.5 & 0.96 & 0.10 \\
\hline & & Weight (kg) & 73.8 (14.6) & 73.3 & $72.1(14.4)$ & 70.5 & 0.96 & 0.01 \\
\hline & & $\mathrm{BMI}\left(\mathrm{kg} / \mathrm{m}^{2}\right)$ & $24.3(3.4)$ & 24.7 & 23.9 (3.3) & 24.3 & 0.89 & 0.23 \\
\hline \multirow{6}{*}{$\begin{array}{l}\text { Obesity } \\
\text { classification }\end{array}$} & \multirow{3}{*}{$\begin{array}{l}\text { Non-overweight }{ }^{1} \\
(n=43)\end{array}$} & Height (cm) & $172.4(9.2)$ & 172.0 & 171.3 (10.9) & 172.0 & 0.92 & 0.22 \\
\hline & & Weight (kg) & 65.1 (9.6) & 66.0 & $64.0(10.4)$ & 64.0 & 0.96 & 0.05 \\
\hline & & BMI $\left(\mathrm{kg} / \mathrm{m}^{2}\right)$ & $21.8(1.8)$ & 21.9 & $21.7(2.4)$ & 21.6 & $0.81^{*}$ & $0.16^{*}$ \\
\hline & \multirow{3}{*}{$\begin{array}{l}\text { Overweight/ } \\
\text { obese }^{2}(n=24)\end{array}$} & Height (cm) & 176.1 (10.6) & 177.5 & $175.1(13.4)$ & 179.5 & 0.96 & 0.15 \\
\hline & & Weight (kg) & 84.5 (13.9) & 83.5 & $81.1(14.6)$ & 80.0 & 0.93 & $<0.01$ \\
\hline & & $\mathrm{BMI}\left(\mathrm{kg} / \mathrm{m}^{2}\right)$ & $27.1(2.1)$ & 26.2 & $26.3(2.3)$ & 25.9 & $0.40^{*}$ & $0.14^{*}$ \\
\hline
\end{tabular}

* Non-parametric equivalent test used (spearman correlation and Wilcoxon signed ranks test).

${ }^{1} \mathrm{BMl}<25 \mathrm{~kg} / \mathrm{m}^{2}$, or BMI less than age-specific cut-offs if under 18 years.

${ }^{2} \mathrm{BMI} \geq 25 \mathrm{~kg} / \mathrm{m}^{2}$, or BMI greater than age-specific cut-offs if under 18 years.

Significant $p$-values $(p<0.05)$ shown in boldface.

SD - standard deviation 
Table 3 Proportion of participants who accurately, under- and over-reported their height and weight stratified by sex, age group, and obesity classification

\begin{tabular}{|c|c|c|c|c|c|c|c|c|c|}
\hline & & & Acc & & Un & & Ov & & p-value ${ }^{4}$ \\
\hline & & & $\mathrm{n}$ & $\%$ & $n$ & $\%$ & $n$ & $\%$ & \\
\hline Height & & Overall & 35 & 52 & 20 & 30 & 12 & 18 & \\
\hline & Sex & Males & 17 & 50 & 8 & 24 & 9 & 26 & 0.16 \\
\hline & & Females & 18 & 55 & 12 & 36 & 3 & 9 & \\
\hline & Age group (years) & $16-19$ & 16 & 48 & 10 & 30 & 7 & 21 & 0.72 \\
\hline & & $20-29$ & 19 & 56 & 10 & 29 & 5 & 15 & \\
\hline & Obesity classification & Non-overweight ${ }^{5}$ & 22 & 54 & 11 & 27 & 8 & 20 & 0.79 \\
\hline & & Overweight/obese ${ }^{6}$ & 13 & 50 & 9 & 35 & 4 & 15 & \\
\hline Weight & & Overall & 23 & 34 & 35 & 52 & 9 & 13 & \\
\hline & Sex & Males & 15 & 44 & 12 & 35 & 7 & 21 & 0.01 \\
\hline & & Females & 8 & 24 & 23 & 70 & 2 & 6 & \\
\hline & Age group (years) & $16-19$ & 13 & 39 & 16 & 48 & 4 & 12 & 0.74 \\
\hline & & $20-29$ & 10 & 29 & 19 & 56 & 5 & 15 & \\
\hline & Obesity classification & Non-overweight ${ }^{5}$ & 17 & 41 & 18 & 44 & 6 & 15 & 0.24 \\
\hline & & Overweight/obese ${ }^{6}$ & 6 & 23 & 17 & 65 & 3 & 12 & \\
\hline
\end{tabular}

${ }^{1}$ Accurate defined as self-report less than two units $(\mathrm{kg}$ or $\mathrm{cm})$ different from measured value.

${ }^{2}$ Under-report defined as self-reported height or weight two or more units $(\mathrm{kg}$ or $\mathrm{cm})$ less than measured value.

${ }^{3}$ Over-report defined as self-reported height or weight two or more units $(\mathrm{kg}$ or $\mathrm{cm}$ ) more than measured value.

${ }^{4}$ Fisher's exact test. Significant p-values shown in bold.

${ }^{5} \mathrm{BMl}<25 \mathrm{~kg} / \mathrm{m}^{2}$ or less than age-specific cut-offs if under 18 years.

${ }^{6} \mathrm{BMI} \geq 25 \mathrm{~kg} / \mathrm{m}^{2}$ or more than age-specific cut-offs if under 18 years.

Significant $p$-values $(p<0.05)$ shown in boldface.

least two kilograms $(\mathrm{p}=0.01)$. Compared to nonoverweight participants, overweight/obese participants were less likely to accurately report weight and more likely to under-report weight, but this was non-significant $(\mathrm{p}=0.24)$.

In total, 3 (9\%) males and 9 (27\%) females inaccurately self-reported their height by five centimetres or more $(\mathrm{p}=0.05)$, and $12(35 \%)$ males and $5(15 \%)$ females inaccurately self-reported their weight by five kilograms or more $(p=0.06)$. Overweight/obese participants were more likely to misreport their weight by at least $5 \mathrm{~kg}$ than non-overweight participants ( $42 \%$ vs $15 \%, \mathrm{p}=0.01$ ).

\section{Classification of overweight/obesity}

Based on self-report data, 22 (33\%) participants were classified as overweight or obese, compared to 26 (39\%) participants based on measured data $(p=0.29)$. In total, $59(88 \%)$ were correctly classified. The sensitivity of selfreported data was $77 \%$ (95\%CI 56\%-91\%) and specificity was $95 \%$ (95\%CI 83\%-99\%).

\section{Discussion}

In this study of young people attending a music festival, we determined the feasibility and accuracy of collecting self-reported height and weight. Our results confirm that at a group level, self-report measures in a community- based setting is a useful tool for estimating the prevalence of overweight and obesity, particularly when impractical to take independent measurements.

Three-quarters of survey participants provided both selfreport height and weight. In the remainder, the majority reported not knowing their height and/or weight, with only a few missing values, although the "don't know" category might have also included some refusals. Of concern, participants who did not self-report their height or weight were systematically different from those who did; they were more likely to be female, younger, and less educated. Because height and weight measurements were not taken for all participants, we could not determine whether self-reporting height and weight was influenced by bodyweight status. Further research is needed to explore if there are biases in bodyweight status influencing willingness and ability to selfreport height and weight in a community-based setting.

Self-reported and measured height did not significantly differ, and approximately half of males and females reported their height within two centimetres of measured height. However, females were more likely than males to underreport their height, and approximately one quarter of females misreported their height by more than five centimetres, compared to only nine percent of males. Previous studies have observed over-report of height [6,7] or decreased accuracy of height with increasing age, perhaps 
due to decreasing opportunities to regularly measure height or changes in height over time [4,27]. Of note, we did not detect a difference in accurate report by age group in our study.

The difference between self-reported and measured weight was more pronounced than for height, particularly among females and overweight or obese individuals. Although one third of all individuals reported their weight within two kilograms of measured weight, a notable $35 \%$ of males and $15 \%$ of females misreported their weight by five or more kilograms. Females were more likely than males to under-report their weight. Our results are consistent with previous studies reporting systematic under-reporting of weight by females and overweight/obese individuals $[4,12]$. It has been postulated that social desirability bias may explain the underreporting of weight, particularly among females and overweight/obese individuals $[8,28]$. However, other research that has included a measure of social desirability has challenged this notion $[26,28]$.

In this study we found that self-report height and weight is a reasonable predictor of overweight and obesity among young people, particularly when pertaining to populationlevel applications such as monitoring trends in overweight, program evaluation, and advocacy for funding [12]. Notwithstanding inaccuracies in the self-reporting of weight, the effect on BMI was small, with the median difference less than one unit. Sensitivity of classification of overweight/obesity was around $77 \%$ - similar to the $70 \%$ found in 15-19 year olds participants of the Australian National Health Survey [6]. Nonetheless, in this sample, approximately two-fifths of overweight/obese individuals would have been incorrectly classified as non-overweight based on self-report (false negatives), which is consistent with previous findings [12]. Methods to limit this inaccuracy and bias might include a correction algorithm to account for generalised misreporting based on certain characteristics $[2,11,29]$, periodically measuring a sub-sample, or where feasible, advising participants ahead of time to weigh and measure themselves before participating [30].

Obesity prevention and control is a national priority in Australia, with increasing millions of dollars being invested to its cause [31]. Community-based settings, including web-based studies, are ideal alternatives to traditional means of population-based recruitment in order to both inform and evaluate obesity interventions - particularly among young adults who are difficult to access through household telephone surveys and school settings. They provide novel means to reach a large number of people, including hard-to-reach populations [32]. In these settings self-reported anthropometric measures are the most practical means to define and estimate the prevalence of overweight and obesity. To our knowledge, this is the first study to investigate accuracy of self-report in a community-based sample; our findings confirm that it is possible to use self-report data to estimate and monitor trends in prevalence of overweight and obesity, particularly when bias is expected to remain constant.

This study has a number of limitations. First, the results are based on a convenience-sample and may not be representative of young people in Australia. Second, the sample size for the independent measurement of height and weight was relatively small and may have limited our ability to detect differences and associations with self-reported height and weight. This sample size was limited by the use of only one measuring station, and in the future we recommend more stations are utilised to obtain a larger sample. Third, small differences in self-reported and measured values may be attributable to non-differential measurement bias; multiple researchers were responsible for taking measurements throughout the day and the recruitment day was characterised by high temperatures, reaching up to 40 degrees Celsius. Some participants may have been dehydrated while others were drinking large quantities of water (the study team was distributing water); both factors may have impacted on the accurate measurement of weight. Natural daily weight fluctuation may also partly explain some weight discrepancies; at the festival measurements were taken between $10 \mathrm{am}-3 \mathrm{pm}$, which may differ to participants' customary time for weighing themselves. Fourth, selection bias may have been introduced because individuals were not systematically randomised to have their height and weight measured by a researcher; there was potential unrecognised selection bias by the investigators inviting participants to be measured, as well in participants who declined to be measured. However, no demographic differences were identified between those with and without measurements taken. Further research is needed to confirm findings in a larger sample and to see whether a convenience music festival audience differs from the general young adult population in terms of self-reported weight and height accuracy.

\section{Conclusions}

In conclusion, our results suggest that the majority of young people participating in a risk behavioural survey are able and willing to self-report their height and weight. The classification of overweight/obesity based on derived self-report BMI has high sensitivity against independent measurement in this setting. Given the wide reach and efficiency of surveys including self-reported measures, these results suggest that that self-reported height and weight are a suitable proxy to estimate the prevalence of overweight and obesity by BMI in a community-based sample of young people, but some underestimation of overweight/obesity is likely and should be taken into consideration. 


\section{Competing interest}

The authors declare that they have no competing interests.

\section{Authors' contributions}

The following co-authors have contributed to the work: $A B$ in data collection, data analysis, manuscript preparation and manuscript review; AP in study design, manuscript preparation and manuscript review; MG in data analysis and manuscript review; RFP in manuscript preparation and manuscript review; MSCL in study design and manuscript review; $\mathrm{MH}$ in study design, manuscript preparation and manuscript review. All authors read and approved the final manuscript.

\section{Acknowledgments}

$\mathrm{MH}$ receives funding from the NH\&MRC; AP is supported by a VicHealth fellowship; RFP is supported by an Australian Postgraduate Award and a Monash/BakerIDI Departmental Scholarship; MSCL receives funding from an NH\&MRC early career research fellowship. The 2011 survey was funded by the Victorian Department of Health. The authors gratefully acknowledge the contribution to this work of the Victorian Operational Infrastructure Support Program. The authors thank Bianca Fiebeger for allowing us to recruit at the Big Day Out music festival, the trained study recruiters, and the study participants. Showbag contents were donated by the Victorian Department of Justice, Marie Stopes International, Youth Projects, Hepatitis Victoria, Department of Health and Ageing, the Free Condom Project and Cadbury Schweppes.

\section{Author details}

${ }^{1}$ Centre for Population Health, Burnet Institute, 85 Commercial Rd, Melbourne, VIC 3004, Australia. ${ }^{2}$ Baker IDI Heart and Diabetes Institute, 99 Commercial Road, Melbourne, VIC 3004, Australia. ${ }^{3}$ Department of Epidemiology \& Preventive Medicine, Faculty of Medicine, Nursing \& Health Sciences, School of Public Health and Preventive Medicine, Monash University, The Alfred Centre, 99 Commercial Road, Melbourne, VIC 3004 , Australia. ${ }^{4}$ Nossal Institute for Global Health, The University of Melbourne, Level 4, Alan Gilbert Building, 161 Barry Street, Carlton, Melbourne, VIC 3010, Australia.

Received: 8 June 2012 Accepted: 22 October 2012 Published: 21 November 2012

\section{References}

1. Australian Insitute of Health and Welfare: Risk Factor Monitoring. A rising epidemic: obesity in Australian children and adolescents. Canberra: Department of Health and Ageing; 2004.

2. Hayes AJ, Kortt MA, Clarke PM, Brandrup JD: Estimating equations to correct self-reported height and weight: implications for prevalence of overweight and obesity in Australia. Aust N Z J Public Health 2008, 32(6):542-545.

3. Gorber SC, Tremblay M, Moher D, Gorber B: A comparison of direct vs. self-report measures for assessing height, weight and body mass index: a systematic review. Obes Rev 2007, 8(4):307-326.

4. Engstrom JL, Paterson SA, Doherty A, Trabulsi M, Speer KL: Accuracy of self-reported height and weight in women: an integrative review of the literature. J Midwifery Womens Health 2003, 48(5):338-345.

5. Himes $\mathrm{JH}$, Hannan P, Wall M, Neumark-Sztainer D: Factors associated with errors in self-reports of stature, weight, and body mass index in Minnesota adolescents. Ann Epidemiol 2005, 15(4):272-278.

6. Wang Z, Patterson CM, Hills AP: A comparison of self-reported and measured height, weight and BMI in Australian adolescents. Aust N Z J Public Health 2002, 26(5):473-478.

7. Elgar FJ, Stewart JM: Validity of self-report screening for overweight and obesity: Evidence from the Canadian Community Health Survey. Can J Public Health 2009, 99(5):423-427.

8. Brener ND, McManus T, Galuska DA, Lowry R, Wechsler H: Reliability and validity of self-reported height and weight among high school students. J Adolesc Health 2003, 32(4):281-287.

9. Roberts RJ: Can self-reported data accurately describe the prevalence of overweight? Public Health 1995, 109(4):275-284.

10. Spencer EA, Appleby PN, Davey GK, Key TJ: Validity of self-reported height and weight in 4808 EPIC?Oxford participants. Public Health Nutr 2002, 5(04):561-565.
11. Nyholm M, Gullberg B, Merlo J, Lundqvist-Persson C, Rastam L, Lindblad U: The validity of obesity based on self-reported weight and height: Implications for population studies. Obesity 2007, 15(1):197-208.

12. Sherry B, Jefferds ME, Grummer-Strawn LM: Accuracy of Adolescent Selfreport of Height and Weight in Assessing Overweight Status: A Literature Review. Arch Pediatr Adolesc Med 2007, 161(12):1154-1161.

13. Taylor AW, Grande ED, Gill TK, Chittleborough CR, Wilson DH, Adams RJ, Grant JF, Phillips P, Appleton S, Ruffin RE: How valid are self-reported height and weight? A comparison between CATI self-report and clinic measurements using a large cohort study. Aust N Z J Public Health 2006, 30(3):238-246.

14. Bolton-Smith C, Woodward M, Tunstall-Pedoe H, Morrison C: Accuracy of the estimated prevalence of obesity from self reported height and weight in an adult Scottish population. J Epidemiol Community Health 2000, 54(2):143-148.

15. Faden VB, Day NL, Windle M, Windle R, Grube JW, Molina BSG, Pelham WE, Gnagy EM, Wilson TK, Jackson KM, et al: Collecting Longitudinal Data Through Childhood, Adolescence, and Young Adulthood: Methodological Challenges. Alcohol Clin Exp Res 2004, 28(2):330-340.

16. Grande E, Taylor A: Sampling and coverage issues of telephone surveys used for collecting health information in Australia: results from a face-toface survey from 1999 to 2008. BMC Med Res Methodol 2010, 10(1):77.

17. Lim MSC, Hellard ME, Aitken CK, Hocking JS: Surveillance of STI risk behaviour among young people attending a music festival in Australia, 2005-08. Aust N Z J Public Health 2009, 33:482-484.

18. Lim MSC, Hellard ME, Hocking JS, Spelman TD, Aitken CK: Surveillance of drug use among young people attending a music festival in Australia, 2005-2008. Drug Alcohol Rev 2010, 29(2):150-156.

19. Lim MSC, Hellard ME, Aitken CK, Hocking JS, Lim MSC, Hellard ME, Aitken CK, Hocking JS: Sexual-risk behaviour, self-perceived risk and knowledge of sexually transmissible infections among young Australians attending a music festival. Sex Health 2007, 4(1):51-56.

20. Lim MSC, Bowring A, Gold J, Hellard ME: What's your 'porn star' name? A novel method of identifying research participants (letter). Sex Transm Dis 2011, 38(2):150-151.

21. National Health and Medical Research Council: Clinical Practice Guidelines for the Management of Overweight and Obesity in Adults. Canberra: NHMRC; 2003.

22. World Health Organization: Obesity: preventing and managing the global epidemic. Report of a WHO consultation. World Health Organ Tech Rep Ser 2000, 894(i-xii):1-253.

23. Cole TJ, Bellizzi MC, Flegal KM, Dietz WH: Establishing a standard definition for child overweight and obesity worldwide: international survey. BMJ 2000, 320(7244):1240.

24. Australian Bureau of Statistics: Australian Standard Geographical Classification (ASGC) Remoteness Areas (cat. no. 1216.0). Canberra: Australian Bureau of Statistics; 2006

25. StataCorp: Stata Statistical Software: Release 11. In A College Station. Edited by. TX: StataCorp LP; 2009.

26. Brestoff J, Perry I, Van den Broeck J: Challenging the role of social norms regarding body weight as an explanation for weight, height, and BMI misreporting biases: Development and application of a new approach to examining misreporting and misclassification bias in surveys. BMC Publ Health 2011, 11(1):331.

27. Australian Bureau of Statistics: How Australians Measure Up (cat. no. 4359.0). Canberra: ABS; 1999.

28. Larson M: Social desirability and self-reported weight and height. Int J Obes 2000, 24(5):663-665.

29. Ezzati M, Martin H, Skjold S, Hoorn SV, Murray CJL: Trends in national and state-level obesity in the USA after correction for self-report bias: analysis of health surveys. JRSM 2006, 99(5):250-257.

30. De Vriendt T, Huybrechts I, Ottevaere C, Van Trimpont I, De Henauw S: Validity of Self-Reported Weight and Height of Adolescents, Its Impact on Classification into BMI-Categories and the Association with Weighing Behaviour. Int J Environ Res Public Health 2009, 6(10):2696-2711.

31. National Health and Medical Research Council: Ovenweight and obesity. http://wuw. nhmrc.gov.au/grants/research-funding-statistics-and-data/overweight-and-obesity.

32. Rhodes SD, Bowie DA, Hergenrather KC: Collecting behavioural data using the world wide web: considerations for researchers. J Epidemiol Community Health 2003, 57(1):68-73.

doi:10.1186/1471-2288-12-175

Cite this article as: Bowring et al:: Measuring the accuracy of selfreported height and weight in a community-based sample of young people. BMC Medical Research Methodology 2012 12:175. 